\title{
Does lack of job satisfaction intensify psychological distress among clinicians, and vice versa?
}

\author{
Khaula Atif ${ }^{1}$, Gholamheidar Teimori Boghsani ${ }^{2}$, Annam Javed $^{3}$, Amna Javed $^{4}$, Sidra Javed ${ }^{5}$
}

\begin{abstract}
Background: To analyze prevalence of job dissatisfaction and psychological distress among doctors with exposure of significant socio-demographic aggravators.

Material and Methods: This descriptive KAP-survey was conducted under the auspices of Pak Emirates Hospital Rawalpindi from Sep $2017-A p r 2018$. Information was collected on a self-designed questionnaire, standardized General Health Questionnaire-12 (GHQ-12) and Job Satisfaction Survey (JSS). Data analyzed via SPSS-21 and $p$-value ( $p<0.05$ considered significant).

Results: Distress and job satisfaction scores were $12.31 \pm 6.33(0-30)$ and $127.28 \pm 29.432(36-201)$ respectively; with a significant positive correlation of job satisfaction with age $(0.288 \&<0.001)$, negative correlation of distress with age $(-0.177 \& 0.008)$ and job satisfaction $(-0.355 \&<0.001)$. Distress was harbored by $20(74.1 \%), 40(55.6 \%)$ and $12(16.7 \%)$ of dissatisfied, indecisive or satisfied participants respectively. Age, marital status, total offspring, job description, working schedules, salaries and work experience significantly affected outcome variables; gender and qualification remained inert. Respondents satisfied with job were less distressed than ambivalent (COR 0.120; 95\% Cl, 0.047-0.304) or dissatisfied (cOR 0.168; 95\% Cl, 0.056-0.506). Conclusion: Perpetual relation between job dissatisfaction and psychological distress was confirmed. All echelons of health care providers must be intermittently screened and managed for psychosomatic perils; every aggravator must also be quarried and catered-for.
\end{abstract}

Keywords: job satisfaction, medical staff, medical evaluation, advance health care planning, developing countries, Pakistan

\section{INTRODUCTION}

Homo sapiens are superlative organisms with explicit interconnection between all organ systems. An individual's physical health casts unambiguous effects on his mental health and vice versa. Role of public health sector in any society cannot be overemphasized (1). It always focuses on prevention and early detection/management of every disease. Occupational susceptibilities often lead to fitness concerns for employees; and sought attention of various local $(2,3)$ and international researchers (4-6). However, impact of professional hazards on psychosomatic aspects of health care providers remained undermined (1). Doctors; the saviors for ill and fragile (2), are invariably anticipated to depict extreme humanity. Paradoxically, they are themselves expected to be devoid of human element, and to serve round the clock simulating machines. The disgraceful trend of verbal and physical abuse towards medical/paramedical personnel exposes them to further insecurity, stress and even regrets on joining medical professional. Unsatisfied or distressed physicians are not just inept to render apt services to their clients; but they also start succumbing to psychosocial challenges $(2,4$, 7). This has been reported to lead to abnormal coping strategies including substance abuse (various drugs/smoking) (8). Occupational dissatisfaction and career distress augment each other; thus a vicious cycle ensues. Correlation between job satisfaction and psychological stress among clinicians has been assessed by local and international researchers ( 3 , 9); yet the data is meager from our region and leaves many stones unturned.

\footnotetext{
1 Health Care Administrator, National University of Medical Sciences, Rawalpindi, Pakistan

2 School of Public Health, Torbat Heydariyeh University of Medical Sciences, Torbat Heydariyeh, Iran

3 Trainee General Medicine, National University of Medical Sciences, Rawalpindi, Pakistan

4 Trainee Emergency Medicine, Shifa International Hospital, Islamabad, Pakistan

5 National University of Medical Sciences, Rawalpindi, Pakistan
}

Correspondence: Khaula Atif

National University of Medical Sciences, Rawalpindi, Pakistan

E-mail: khaulaatifkhan@gmail.com

Received: 15 Apr 2018, Accepted: 22 Jun 2018

(C) 2018 by the authors; licensee Modestum Ltd., UK. This article is an open access article distributed under the terms and conditions of the Creative Commons Attribution License (http://creativecommons.org/licenses/by/4.0/). 
Pak Emirates Hospital Rawalpindi; is a state of art government tertiary-care unit; where doctors from a spectrum of socio-economic credentials and multi-ethnicities serves. All clinicians serve during morning hours; while private practice is allowed to consultants with deposition of a fixed proportion of their fee to government treasury. Every employee receives his paychecks on monthly basis. This survey aimed to analyze effects of socio-demographic features on professional satisfaction and psychological distress among doctors and correlation between outcome variables. It was hypothesized that considerable job dissatisfaction and stress must be present among unscreened and undiagnosed participants. Question posed were; which personal factors cast significant effects on dependent variables. As a pioneer research from concerned region, authors hoped that drawn inferences will lead to advancement in screening/management of eligible staff and conduction of better studies in future.

\section{METHODS}

Under the kind auspices of Pak Emirates Hospital Rawalpindi, Pakistan, this simple descriptive KAP-survey was conducted from Sep 2017-Apr 2018. Formal approval of ethical review board was sought; procedures of this study accorded with principles of declaration of Helsinki (1964) and its later amendments. Adapting non-purposive convenience sampling technique, doctors serving in concerned hospital for at least six months were incorporated; those with diagnosed psycho-somatic disorders or any other chronic/debilitating ailments were excluded.

This research had 3 parts. Firstly, preceded by informed consent, socio-demographic information (age, gender, marital status, total offspring, qualification, work experience, job description, weekly working hours, monthly paychecks) was endorsed on a semi-structured, self-designed and contextually revised questionnaire. Then standardized General Health Questionnaire was filled (GHQ-12, Goldberg and Williams', 1988) (10); which is an internationally acknowledged and reliable tool to measure psychological distress $(8,11)$, with a Cronbach' alpha Coefficient of 0.9 (12). It relates to the three dimensions, 06 items to Social Dysfunction, 04 items to Anxiety \& Depression and last 02 items to Loss of confidence with a 4 points Likert's scaling $(0,1,2,3)(10)$. No distress, Distress and Severe Distress were considered on scores $<14,14$ 19 and $>20$ respectively. Lastly, Job Satisfaction Survey (JSS) was endorsed which is a commonly utilized multidimensional instrument (13). It was originally developed by Paul Spector to measure job satisfaction in organizations encompassing social service, human service and other sectors (14). It comprehends nine dimensions of satisfaction(pay, promotion, supervision, benefits, contingent rewards, operating procedures, co-workers, nature of work and communication) with six six-point Likert's scale (14). JSS is potentially apposite for health service personnel working in government-run facilities. Its validity and reliability are 0.70 and 0.86 Cronbach's Alpha Coefficient respectively (15). Scores 36-108, 108144 and 144-216 meant dissatisfied, ambivalent/indecisive and satisfied respectively.

Pilot testing on first 20 samples was done. Prior estimation of non-response rate was $60 \%$; therefore, 900 sets of forms were distributed. Those collected back and complete in all aspects were analyzed. Participation was voluntary and purpose of study was explained to all doctors. It was undertaken to not to record any individual identifiers (name, address, contact number etc.) and to destroy all forms after completion of study. Nevertheless, respondents keen to know their scores were welcomed to endorse their personal particulars and contact back.

Data analyzed via descriptive analysis (SPSS-21), quantitative data expressed as mean \pm standard deviation/SD (range minimum-maximum); summed-up as frequency (percentage). Cross-tabulation was done via chi-square analyses. Pearson Bivariate 2-tailed Correlation was utilized to find association between numeric data; its results expressed as Pearson Correlation \& p-Value. Univariate logistic regression was performed to determine the rates of psychological distress between different participants' characteristics. Significant variables were sifted for multivariable logistic regression analyses to further explore this association, which provided odds ratio (OR). Inferences based on OR and pvalues, level of significance was considered $p<0.05$.

\section{RESULTS}

Response rate was $26.2 \%$ as 236 forms were received back. Of them, 221 were completely filled and segregated for further analyses. Numeric data was; Age in years 33.65 \pm 10.27 (23-64): GHQ-12 scores $12.31 \pm 6.33$ (0-30): and JSS scores $127.28 \pm 29.432$ (36-201). There was a significant positive correlation of job satisfaction with age $(0.288 \&<0.001)$, negative correlation of distress with age $(-0.177 \& 0.008)$ and job satisfaction $(-0.355 \&<0.001)$.

Qualitative characteristics and their relation with levels of job satisfaction are illustrated in Table 1; 27 (12.2\%) were dissatisfied, 157 (71.0\%) ambivalent and 37 (16.7\%) satisfied; while no distress, distress and severe distress were found in $149(67.4 \%), 44(19.9 \%)$ and $28(12.7 \%)$ respondents respectively. Significantly more satisfied were married $(p<0.001)$, 
Table 1: Socio-demographic characteristics of the respondents and their relation with Job Satisfaction $(N=221)$



a means "Frequency", b means "Percent" and c means "Member or Fellow College of Physicians and Surgeons Pakistan Or Equivalent", $d$ means House Officer, e means Medical Officer



Figure 1: Dissatisfied doctors reveals significantly higher scores for psychological distress

more in age $(p-0.003)$, had more work experience $(p<0.001)$, received paycheck income $>100,000 \mathrm{PKR} / \mathrm{month}(p<0.001)$. Contrarily, issueless ( $p-0.017)$, house offices ( $p 0.015)$ or those working $>80$ hours/week $(p-0.004)$ were more dissatisfied. Gender ( $p-.051)$ and qualification ( $p-.074)$ did not significantly affect occupational satisfaction levels. Figure 1 elucidates that dissatisfied subjects revealed higher scores of distress. 
Table 2: Univariate logistic regression of factors associated with psychological distress

\begin{tabular}{|c|c|c|c|c|c|c|}
\hline \multirow{2}{*}{\multicolumn{2}{|c|}{ Characteristics }} & \multicolumn{2}{|c|}{ Distress } & \multirow{3}{*}{$\frac{\mathbf{C O R}^{\mathbf{b}}}{1.000}$} & \multirow{2}{*}{$95 \% \mathrm{Cl}^{\mathrm{c}}$} & \multirow{2}{*}{$p$-value } \\
\hline & & $\mathrm{No}^{\mathrm{a}}$ & Yes $^{\mathrm{a}}$ & & & \\
\hline \multirow{2}{*}{ Gender } & Male & $87(72.5)$ & $33(27.5)$ & & & \\
\hline & Female & $62(61.4)$ & $39(38.6)$ & 0.603 & $0.342-1.063$ & 0.080 \\
\hline \multirow{3}{*}{ Age (Years) } & $<30$ & $67(67)$ & $33(33)$ & 1.000 & & \\
\hline & $30-50$ & $59(61.5)$ & $37(38.5)$ & 1.273 & $0.709-2.286$ & 0.419 \\
\hline & $>50$ & $23(92)$ & $2(8)$ & 0.177 & $0.039-0.794$ & $0.024^{*}$ \\
\hline \multirow{2}{*}{ Marital Status } & Single & $49(65.3)$ & $26(34.7)$ & 1.000 & & \\
\hline & Married & $100(68.5)$ & $46(31.5)$ & 1.154 & $0.639-2.081$ & 0.635 \\
\hline \multirow{3}{*}{ Offspring } & $\mathrm{Nil}$ & $74(65.5)$ & $39(34.5)$ & 1.000 & & \\
\hline & $1-2$ & $31(70.5)$ & $13(29.5)$ & 0.796 & $0.374-1.693$ & 0.553 \\
\hline & $\geq 3$ & $44(68.8)$ & $20(64)$ & 0.862 & $0.448-1.661$ & 0.658 \\
\hline \multirow{3}{*}{ Qualification } & MBBS & $92(64.8)$ & $50(35.2)$ & 1.000 & & \\
\hline & MCPS & $7(77.8)$ & $2(22.2)$ & 0.433 & $0.105-2.627$ & 0.526 \\
\hline & FCPS & $50(71.4)$ & $20(28.6)$ & 0.334 & $0.395-1.372$ & 0.736 \\
\hline \multirow{3}{*}{ Work Experience } & $<5$ & $70(66.7)$ & $35(33.3)$ & 1.000 & & \\
\hline & $6-20$ & $44(59.5)$ & $30(40.5)$ & 1.364 & $0.736-2.526$ & 0.324 \\
\hline & $>20$ & $35(83.3)$ & $7(16.7)$ & 0.400 & $0.161-0.991$ & $0.048^{*}$ \\
\hline \multirow{4}{*}{ Job Description } & $\mathrm{HO}$ & $44(64.7)$ & $24(35.3)$ & 1.000 & & \\
\hline & $\mathrm{MO}$ & $34(85)$ & $6(15)$ & 0.324 & $0.119-0.880$ & $0.027^{*}$ \\
\hline & Trainee & $29(53.7)$ & $25(46.3)$ & 1.58 & $0.761-3.281$ & 0.219 \\
\hline & Consultant & $42(71.2)$ & $17(28.8)$ & 0.742 & $0.350-1.573$ & 0.437 \\
\hline \multirow{4}{*}{$\begin{array}{l}\text { Weekly Working } \\
\text { Hours }\end{array}$} & $<40$ & $10(66.7)$ & $5(33.3)$ & 1.000 & & \\
\hline & $40-60$ & $41(75.9)$ & $13(24.1)$ & 0.634 & $0.183-2.195$ & 0.472 \\
\hline & $60-80$ & $20(76.9)$ & $6(23.1)$ & 0.600 & $0.147-2.455$ & 0.477 \\
\hline & $>80$ & $78(61.9)$ & $48(38.1)$ & 1.231 & $0.397-3.818$ & 0.719 \\
\hline \multirow{3}{*}{$\begin{array}{l}\text { Paychecks (Thousands } \\
\text { PKR/month) }\end{array}$} & $<50$ & $72(69.2)$ & $32(30.8)$ & 1.000 & & \\
\hline & $50-100$ & $40(62.5)$ & $24(37.5)$ & 1.350 & $0.701-2.600$ & 0.369 \\
\hline & $>100$ & $37(69.8)$ & $16(30.2)$ & 0.973 & $0.474-1.997$ & 0.940 \\
\hline \multirow{3}{*}{ Job Satisfaction } & Dissatisfied & $7(25.9)$ & $20(74.1)$ & 1.000 & & \\
\hline & Ambivalent & $117(74.5)$ & $40(25.5)$ & 0.120 & $0.047-0.304$ & $<0.001^{*}$ \\
\hline & Satisfied & $25(67.6)$ & $12(32.4)$ & 0.168 & $0.056-0.506$ & $<0.001^{*}$ \\
\hline
\end{tabular}

Data expressed as $a=$ Frequency(Percent, $b=$ Crude Odds Ratio $\& c=$ Confidence Interval; ${ }^{*}$ Significant at level $p<0.05$

Table 2 highlights associations of distress and univariate logistic regression analysis along with unadjusted odd ratio (cOR). Amongst distressed (32.6\%), majority were $30-50$ years old (38.5\%), single (34.7\%), trainee (46.3\%), had more children (64\%), 6-20 years' work experience (40.5\%), or were working for $>80$ hours/week (38.1\%). Similarly; distress was harbored by $20(74.1 \%), 40(55.6 \%)$ and $12(16.7 \%)$ of dissatisfied, indecisive or satisfied participants respectively. Respondents aging $>50$ years ( $\mathrm{COR} 0.177 ; 95 \% \mathrm{Cl}, 0.039-0.794$ ), with $>20$ years work experience (cOR $0.4 ; 95 \% \mathrm{Cl}, 0.161$ 0.991 ) and ambivalent with job as compared to dissatisfied (COR 0.120; $95 \% \mathrm{Cl}, 0.047-0.304$ ) and satisfied (COR 0.168; $95 \% \mathrm{Cl}, 0.056-0.506$ ) were less likely to be distressed. Medical Officers (cOR $0.324 ; 95 \% \mathrm{Cl}, 0.119-0.880$ ) were more distressed than their correspondents.

Multivariate logistic regression analysis elaborating risk/prevalence of distress is depicted in Table 3. Age, work experience or job description did not cast significant impact $(p>0.05)$. However, ambivalent and satisfied participants were less likely to be distressed (aOR $0.105 ; 95 \% \mathrm{Cl}, 0.039-0.283) \&(a O R \quad 0.059 ; 95 \% \mathrm{Cl}, 0.059-0.678)$ respectively. Participants aging 30-50 years were at higher risk (aOR 1.346; 95\% Cl, 0.332-5.453) and aging $>50$ years at lower risk (aOR 0.216; 95\% Cl, 0.021-2.251) than rest. Doctors with 6-20 and >20 years work experience harbored higher prevalence (aOR $1.357 ; 95 \% \mathrm{Cl}, 0.433-4.253) \&(\mathrm{aOR} 1.77 ; 95 \% \mathrm{Cl}, 0.349-8.975)$ respectively; just like trainees compared to HouseOfficers (aOR $1.711 ; 95 \% \mathrm{Cl}, 0.591-4.954)$. 
Table 3: Multiple logistic regression analysis of factors associated with psychological distress

\begin{tabular}{|c|c|c|c|c|c|c|c|}
\hline \multicolumn{2}{|c|}{ Characteristics* } & $\boldsymbol{\beta}$ & S.E & Wald & OR & $95 \% \mathrm{Cl}$ & $p$-value \\
\hline \multirow{3}{*}{ Job Satisfaction } & Dissatisfied & & & & 1.000 & & \\
\hline & Ambivalent & -2.156 & 0.507 & 19.808 & 0.105 & $0.039-0.283$ & $<0.001$ \\
\hline & Satisfied & -1.607 & 0.622 & 6.679 & 0.059 & $0.059-0.678$ & 0.010 \\
\hline \multirow{3}{*}{ Age (Years) } & $<30$ & & & & 1.000 & & \\
\hline & $30-50$ & 0.364 & 0.722 & 0.253 & 1.438 & $0.349-5.925$ & 0.615 \\
\hline & $>50$ & -1.411 & 1.198 & 1.387 & 0.244 & $0.023-2.554$ & 0.239 \\
\hline \multirow{3}{*}{ Work Experience } & $<5$ & & & & 1.000 & & \\
\hline & $6-20$ & 0.328 & 0.589 & 0.311 & 1.388 & $0.438-4.403$ & 0.577 \\
\hline & $>20$ & 0.321 & 0.855 & 0.141 & 1.378 & $0.258-7.371$ & 0.707 \\
\hline \multirow{4}{*}{ Job Description } & $\mathrm{HO}$ & & & & 1.000 & & \\
\hline & $\mathrm{MO}$ & -0.893 & 0.696 & 1.648 & 0.409 & $0.105-1.601$ & 0.199 \\
\hline & Trainee & 0.477 & 0.547 & 0.760 & 1.611 & $0.552-4.702$ & 0.383 \\
\hline & Consultant & -0.362 & 0.685 & 0.279 & 0.696 & $0.182-2.665$ & 0.597 \\
\hline
\end{tabular}

*Reference group; Job satisfaction unsatisfied, Age <30yrs, Years of Service <5yrs, Nature of Job HO; $\beta$ represents the logistic regression coefficient; S.E: represents the standard error

\section{DISCUSSION}

Doctors are the linchpin to a healthy society. They manipulate with humans; therefore their mental status should be more precise and resilient than other professionals. Dealing with death and disease exposes them to tremendous psychological insults (2). Incongruously, situations mandate humane as well as callous response from them simultaneously. Occupational dissatisfaction among medical/paramedical staff directly affects their services; casting indirect impacts on the health outcomes of their clients/patients $(2,4,7,16,17)$.

A modest response rate in this survey once compared to other researches $(7,9,13)$ might partially be due to lack of interest towards collection of medical evidence; yet unambiguous feature remains their hectic schedules. Anyone serving his patients tirelessly may find it difficult to spare time for such ventures. This study presents prevalence of job dissatisfaction and psychological distress among Pakistani doctors. The results showed that only $37(16.74 \%)$ participants were satisfied with their work; 72 (32.57\%) being psychologically distressed. Literature revealed that among Pakistani doctors, 10\% (7) and 31\% (2) proclaimed professional dissatisfaction and psychological stress respectively. In China, deteriorating levels of job satisfaction were revealed among clinicians (9); while $25 \%$ endorsed career burnout (9). Almost $40 \%$ of Indian doctors also felt stressed at workplace (8). Doctors invariable develop psycho-emotional attachment with their clients. Despite having more patient-centeredness, they have been reported to have lesser work satisfaction and more distress than other paramedical staff (13).

In subject data, prevalence of psychological distress among dissatisfied, ambivalent and satisfied subjects was $74.1 \%$, 25.5 and $32.4 \%$, respectively; satisfied being $94.1 \%$ less likely to develop stress. Subjects with job dissatisfied had higher odds of psychological distress than others. Literatures concurred similar associations $(2,5,9,18)$.

Various researchers reconnoitered challengers for clinicians' mental fitness. In this study, age, marital status, total offspring, job description, working schedules, salaries and work experience significantly affected outcome variables; gender and qualification remained more passive. Univariate logistic regression demonstrated that respondents who were middle-aged (30-50 years), were trainees in their respective faculties and those with more work experience, more working hours or more children were more likely to harbor psychological distress. Multivariate regression further elaborated supplementary distress among doctors who were middle-aged, had more job experience or were undergoing training. Comparable results have been documented from Pakistan $(2,7)$; where mainstream health service providers were satisfied with supervisors/colleagues and job description, but low salaries/benefits/rewards, communication matters, working conditions $(15,19)$ and lack of service structure $(20)$ abetted occupational satiety. Scientist labeled workplace as one of the most important factor to affect doctors; more satisfied being males, older, serving in preclinical/para-clinical departments and having infrequent departmental displacements/postings (21). HAM et al. found that diversity of work, positive collegial interactions and teaching experience garnish job satisfaction; while low-slung income, extended working hours/duties, time management disputes and lack of recognition attenuate it (22). Over-work, specific specialties and VIP-culture in clinical set-ups also fetch undue stress (8).

Authors could not evade every limitation. Results should be generalized with cautious due to incorporation of single health-care center, limited sample size and selection bias. Outcomes among doctors serving in different 
departments/specialties were not ghettoized which could have rendered radical inferences. Nevertheless, it's the first survey of its type being carried out in a major metropolitan city of a developing country. Hypothesis was concurred and questions posed were retorted by reliable data. Majority of relevant variables were incorporated and revealed their significance. This survey may trigger similar researches encompassing expanded variables and varied sample at local, regional and international platforms.

\section{CONCLUSION}

Perpetual relation between job dissatisfaction and psychological distress was confirmed. Medical and paramedical personnel serving at all tiers must be regularly screened for psychological challengers; those with positive scores must be aptly and timely managed. Every modifiable aggravator must be excavated and addressed, coping skills of suffers or en-risked must be polished. Reliable and validated instruments like GHQ-12 and JSS must be incorporated in advanced health care planning medical evaluation procedures.

\section{ACKNOWLEDGEMENT}

All doctors who rendered their precious time and kindly participated in this survey to make it a success.

\section{REFERENCES}

1. Organization WH. Health Systems Profile- Pakistan. Regional Health Systems Observatory- EMRO Cairo. 2007.

2. Atif $\mathrm{K}$, Khan HU, Malik AF. Do doctors have hidden distress; a study conducted at tertiary care hospital at Lahore. JPMA. 2016;66(63). PMid: 26712184

3. Chatta HA, Zafar A, Amin F. Measurement of Stress among Doctors in Surgical Intensive Care Unit (ICU) of Lahore General Hospital, Lahore. Pakistan Journal of Medical \& Health Sciences. 2017;11(3):874-7.

4. Agarwal $M$, Sharma A. Effects of hospital workplace factors on the psychological well-being and job satisfaction of health care employees. Journal of Health Management. 2011;13(4):439-61. https://doi.org/10.1177/097206341101300405

5. Amati M, Tomasetti M, Ciuccarelli M, Mariotti L, Tarquini LM, Bracci M, et al. Relationship of job satisfaction, psychological distress and stress-related biological parameters among healthy nurses: a longitudinal study. Journal of Occupational Health. 2010;52(1):31-8. https://doi.org/10.1539/joh.L9042 PMid:20032591

6. Gong Y, Han T, Chen W, Dib HH, Yang G, Zhuang R, et al. Prevalence of anxiety and depressive symptoms and related risk factors among physicians in China: a cross-sectional study. PloS one. 2014;9(7):e103242. https://doi.org/10.1371/journal.pone.0103242 PMid:25050618 PMCid:PMC4106870

7. Atif $\mathrm{K}$, Khan HU, Maqbool S. Job satisfaction among doctors, a multi-faceted subject studied at a tertiary care hospital in Lahore. Pakistan Journal of Medical Sciences. 2015;31(3):610. http://dx.doi.org/10.12669/pjms.313. 7402 PMid:26150854. PMCid:PMC4485281

8. Amte R, Munta K, Gopal PB. Stress levels of critical care doctors in India: a national survey. Indian journal of critical care medicine: peer-reviewed, official publication of Indian Society of Critical Care Medicine. 2015;19(5):257. https://doi.org/10.4103/0972-5229.156464 PMid:25983431 PMCid:PMC4430743

9. Xiao Y, Wang J, Chen S, Wu Z, Cai J, Weng Z, et al. Psychological distress, burnout level and job satisfaction in emergency medicine: a cross-sectional study of physicians in China. Emergency Medicine Australasia. 2014;26(6):538-42. https://doi.org/10.1111/1742-6723.12315 PMid:25319720

10. Goldberg D, Williams P. A user's guide to the GHQ. Windsor: NFER-Nelson. 1988.

11. Boyd $C M$, Bakker $A B$, Pignata $S$, Winefield AH, Gillespie N, Stough C. A longitudinal test of the job demandsresources model among Australian university academics. Applied Psychology. 2011;60(1):112-40. https://doi.org/10.1111/j.1464-0597.2010.00429.x

12. Khan A, Shah IM, Khan F, Suhail S. Reliability and Validity Assessment of 12 Items General Health Questionnaire (GHQ: 12) among Pakistani University Teachers. World Applied Sciences Journal. 2013;24(5):603-8.

13. Chan $\mathrm{CMH}$, Ahmad WAW, Yusof MM, Ho GF, Krupat E. Patient-Centredness, Job Satisfaction and Psychological Distress: a Brief Survey Comparing Oncology Nurses and Doctors. Asian Pacific Journal of Cancer Prevention. 2015;16(16):6895-8. https://doi.org/10.7314/APJCP.2015.16.16.6895 PMid:26514463 
14. Spector PE. Measurement of human service staff satisfaction: Development of the Job Satisfaction Survey. American Journal of Community Psychology. 1985;13(6):693-713. https://doi.org/10.1007/BF00929796 PMid:4083275

15. Tasneem S, Cagatan AS, Avci MZ, Basustaoglu AC. Job Satisfaction of Health Service Providers Working in a Public Tertiary Care Hospital of Pakistan. The Open Public Health Journal. 2018;11(1). https://doi.org/10.2174/1874944501811010017

16. Utsugi-Ozaki M, Bito S, Matsumura S, Hayashino Y, Fukuhara S, Group M-JS. Physician job satisfaction and quality of care among hospital employed physicians in Japan. Journal of General Internal Medicine. 2009;24(3):387-92. https://doi.org/10.1007/s11606-008-0886-4 PMid:19130149 PMCid:PMC2642562

17. Vermeir P, Degroote S, Vandijck D, Mariman A, Deveugele M, Peleman R, et al. Job Satisfaction in Relation to Communication in Health Care Among Nurses: A Narrative Review and Practical Recommendations. SAGE Open. 2017;7(2):2158244017711486. https://doi.org/10.1177/2158244017711486

18. Foley M, Lee J, Wilson L, Cureton VY, Canham D. A multi-factor analysis of job satisfaction among school nurses. The Journal of School Nursing. 2004;20(2):94-100. https://doi.org/10.1177/10598405040200020701 PMid:15040765

19. Kumar R, Ahmed J, Shaikh BT, Hafeez R, Hafeez A. Job satisfaction among public health professionals working in public sector: a cross sectional study from Pakistan. Human Resources for Health. 2013;11(1):2. https://doi.org/10.1186/1478-4491-11-2 PMid:23298253 PMCid:PMC3554587

20. Ghazali SSA, Shah IA, Zaidi SAA, Tahir M. Job satisfaction among doctors working at teaching hospital of Bahawalpur, Pakistan. J Ayub Med Coll Abbottabad. 2007;19(3):81-3. PMid: 8444590

21. Bhattacherjee S, Ray K, Roy JK, Mukherjee A, Roy H, Datta S. Job satisfaction among doctors of a government medical college and hospital of Eastern India. Nepal Journal of Epidemiology. 2016;6(3):596. https://doi.org/10.3126/nje.v6i3.14762 PMid:27822405 PMCid:PMC5082489

22. Van Ham I, Verhoeven AA, Groenier KH, Groothoff JW, De Haan J. Job satisfaction among general practitioners: a systematic literature review. The European Journal of General Practice. 2006;12(4):174-80. https://doi.org/10.1080/13814780600994376 PMid:17127604

$\diamond \diamond \diamond \diamond \diamond \diamond \diamond$

http://www.ejgm.co.uk 